\title{
DETERMINATION OF MAXIMUM TORQUE DURING CARPENTRY WASTE COMMINUTION
}

\author{
Eukasz Warguea, Mateusz Kukla \\ Poznan University of Technology \\ Poland \\ (Recieved December 20i9)
}

\begin{abstract}
In order to elaborate design guidelines for developing efficient and possibly most energy saving mills for comminuting carpentry, OSB and MDF waste, there have been performed some tests aimed at torque demand on the working unit of the machinery participating in that process. The tests were carried out on a cylindrical wood chipper. There were indicated the maximum, minimum and average values of the torque, indispensable for the comminution of boards with defined geometric sizes ( $5-50 \mathrm{~mm}$ wide $)$ and thickness $(3-28 \mathrm{~mm}$ ). The value of torque required in the comminution of carpentry waste increases with growing cross section, and the torque vs. cross section relation is approximately linear. The presented values may constitute not only a set of input data indispensable for modeling the power which is necessary for the comminution process, but they can also enable the validation of the existing cutting models with a single cylinder cutter.
\end{abstract}

KEYWORDS: Cutting forces, wood chipper, MDF board, OSB board, chipboard, carpentry waste, comminuting mill.

\section{INTRODUCTION}

Consumerism intensifies worldwide, which leads to increased demand for new household furnishings and is reflected in increased sales volumes in the furniture industry. According to the 2021 year estimates, this trend will continue (Pavlov 2019). In consequence, the volume of carpentry waste increases. Main waste in today's carpentry workshops are furniture boards consisting, first of all, of chips and wood dusts in PCV laminates (Narlıoglu et al. 2018). Most used furniture materials are as follows: furniture grade plywood, chip boards, fiber boards including oriented strand boards (OSB), low density fiberboards (LDF), medium density fiberboards (MDF) or high density fiber boards (HDF) (Wasielewski 2019). Such materials are made mainly of wood fibers and contain up to $10 \%$ of synthetic additives, like glues, laminates, varnishes and surface modifiers (Stubdrup et al. 2016, Wasielewski 2019). Because of the materials used in the manufacturing process, there will occur problematic waste which needs appropriate utilization. 
Chemical energy contained in the waste may be utilized for energy generation purposes, viz. electricity or thermal energy in various technological variants of thermochemical convection, e.g. incineration, pyrolysis, gasification, plasma processes and their combinations (Król 2008, Wasielewski and Bałazińska 2017). Moreover, such a type of waste is characterized with high contents of wood - a biodegradable fraction - which may mean extra profits in relation to the qualification and clearing of generated electricity as such which, to a certain extent, comes from renewable sources (Wasielewski and Bałazińska 2017). For a possible environmental hazard, the energy recovered from waste is subject to particular legislative determinants (Wasielewski and Bałazińska 2017). They regard mainly the processing requirements related to the management of emission measurements and compliance with the emission standards (Wasielewski and Bałazińska 2017). Industrial waste is incinerated in purpose-built installations which limit the volume of deleterious substances released into the air, of which gravest concern are dusts, fly ashes, acid gases as well as aerosols of heavy metals (Król 2008). Both appropriate selection of incineration parameters and the application of correct technology of waste gas cleaning may guarantee a low emission heat source for industrial establishments (Karol 2008). Factory furnaces, used in such processes, are adapted to the incineration of comminuted fiber board and wood-based waste, and are characterized with high temperatures in the burning chamber (at least $850^{\circ} \mathrm{C}$ ) as well as an after-burning chamber with additional burners. Such modern facilities are adapted to the incineration of comminuted waste. It is easier to transport commuted waste (Reczulski 2015), to store it and eventually to support incineration technologies. In the references available there are some results of the investigations into the materials used in furniture production. Those results concern mechanical and physical properties of furniture boards with diversified analyses and structures (Pritchard et al. 2001, Akyüz et al. 2010, de Barros Filho et al. 2011, Ayrilmis et al. 2007, Ganey et al. 2007, Rydzkowski and Michalska-Pożoga 2016, Akyildiz et al. 2018). Then, there are also published models which allow estimating forces in the process of cutting or machining wood or wood-based materials on such machines, like a circular saw (Porankiewicz et al. 2011, Orłowski et al. 2013, Kopecký et al. 2014), a band saw (Orłowski and Ochrymiuk 2017, Chuchała and Orłowski 2018), a chain saw (Kuvik et al. 2017), a large size crusher (Yu et al. 2012), a milling machine (Džinčić et al. 2012, Guo et al. 2015, Mandić et al. 2015, Krauss et al. 2016, Durkowić et al. 2018, Kopecký et al. 2019), as well as in the case of cutting along the direction pre-determined in relation to the specimen (Porankiewicz and Goli 2014). Nevertheless, there is no information available for designers of mills comminuting furniture waste, and precisely, about the forces to be carried by their working units, and thus, also about the power demand for the drives. Adequate selection of the driving unit without great power reserve is reflected in quantifiable ecological and economic benefits related to saving the energy in the process under execution (Waluś et al. 2018, Warguła et al. 2019). This article presents average torque values for comminuting carpenter waste - laminated particle board (PB-L) and non-laminated PB boards, OSB and MDF with a single cylinder wood chipper. The effect of the number of cutting blades upon the torque was also proved. The final results are to be used in future for developing and validating a model and for determining the maximum power indispensable for the execution of furniture waste comminution with a single cylinder wood chipper.

\section{MATERIALS AND METHODS}

Waste wood-based furniture boards were selected for test specimens. They were segregated and ranked in line with Tab. 1, taking into consideration the type of material, its thickness and width. From among waste products, there were selected particle boards made of wood chips 
bonded with each other with synthetic glues and pressed at a high temperature. Those boards were also divided according to the presence or absence of an external laminate. Another group of particle boards were OSB made of relatively big, oblong chips, juxtaposed with longitudinal axes arranged in one direction of the sheet. The last group of boards subject to investigation was MDF. They are dry shaped and their density lies in an interval from $500 \mathrm{~kg} \cdot \mathrm{m}^{-3}$ to $900 \mathrm{~kg} \cdot \mathrm{m}^{-3}$. The samples under tests were subject to conditioning, and their humidity did not exceed $4 \%$.

Tab. 1: Materials subjected to comminution.

\begin{tabular}{|c|c|c|c|c|c|c|c|c|c|c|c|c|c|c|}
\hline Type of board & \multicolumn{5}{|c|}{ Thickness (mm) } & \multicolumn{9}{|c|}{ Width (mm) } \\
\hline Particle board with laminate (PB-L) & 10 & & 8 & & 8 & \multirow{4}{*}{10} & \multirow{4}{*}{15} & \multirow{4}{*}{20} & \multirow{4}{*}{25} & \multirow{4}{*}{30} & \multirow{4}{*}{35} & \multirow{4}{*}{40} & \multirow{4}{*}{45} & \multirow{4}{*}{50} \\
\hline Particle board without laminate (PB) & 12 & & 8 & \multicolumn{2}{|c|}{25} & & & & & & & & & \\
\hline Oriented strand board (OSB), & 12 & \multicolumn{2}{|c|}{16} & 18 & 26 & & & & & & & & & \\
\hline Medium density fiberboard (MDF) & 3 & 8 & 10 & 14 & 20 & & & & & & & & & \\
\hline
\end{tabular}

The experiments were carried out on a test stand for investigating into wood comminution processes (Warguła et al. 2018). That stand was based upon a Macalister MQS2800 electric comminuting mill, designed for wood comminution (Fig. 1).
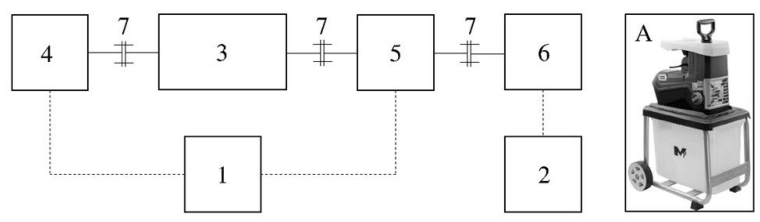

Fig. 1: Scheme of the test stand: 1 - recording computer, 2 - wood chipper controller, 3 - working unit, 4-RPM sensor, 5 - torque measurement device, 6-drive motor, 7 - clutch; detail A shows the cylinder wood chipper before fitting the measurement devices.

In order to enable investigations into kinetic and dynamic properties of the comminution process, the wood chipper was supplemented with measurement devices. The torque characteristic was measured and recorded by means of a versatile torque measurement device. The rotational speed was measured with a Megatron MOB 2500/5/BZ/N encoder. Data acquisition was possible due to dedicated proprietary computer software. In each measurement test, 10 specimens, with pre-determined properties, geometry and material, were examined as presented in Tab. 1.

\section{RESULTS AND DISCUSSION}

The results of the tests performed include time functions for the torque and rotational speed of the working unit. Selected curves for the recorded results are shown in Fig. 2. From the time interval in which the comminution process was performed (interval d) determined was a series of maximum torque values. The arithmetic mean of those values was taken as the estimator for the value to be found. 


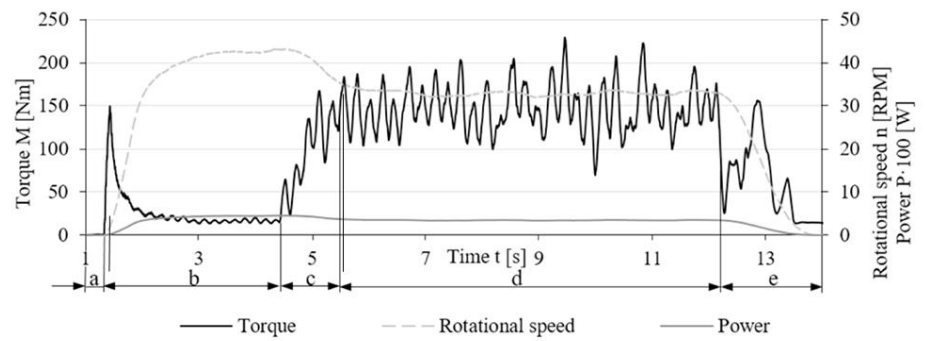

Fig. 2: Torque vs. time and RPM vs. time curves for the comminution of a laminated particle board $18 \mathrm{~mm}$ thick and $50 \mathrm{~mm}$ wide; indicated are some selected process intervals: a - machine switched off, $b$-mill start-up, $c$-comminution started, $d$-comminution in course, $e-$ comminution ended.

The selected torque vs. time curve during the comminution process indicating both the maximum values occurring in the cutting process and the determined arithmetic mean of the maximum torque were shown in Fig. 3.

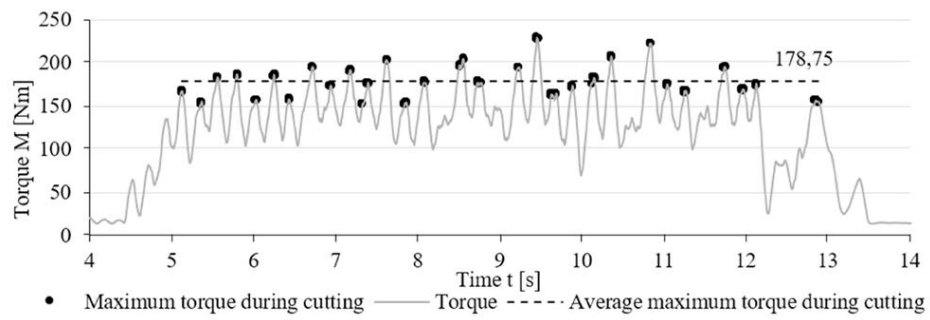

Fig. 3: Torque vs. time curve for the comminution of a laminated particle board $18 \mathrm{~mm}$ thick and $50 \mathrm{~mm}$ wide; indicated are the maximum values for the cutting process, with the determination of the arithmetic value.

Basing upon the collected curves there were determined the average maximum torque values for the comminution of furniture boards, and indicated were the maximum and minimum values (Tabs. 2-4).

Tab. 2: Maximum torque value for the comminution of a $P B$ and a laminated $P B-L$, where: $A-$ width, $B$-arithmetic mean, $C$-maximum value, $D$ - minimum value.

\begin{tabular}{|c|c|c|c|c|c|c|}
\hline \multicolumn{7}{|c|}{ Particle Board } \\
\hline & \multicolumn{3}{|c|}{ with laminate } & \multicolumn{3}{|c|}{ without laminate } \\
\hline A & B & $\mathrm{C}$ & $\mathrm{D}$ & B & $\mathrm{C}$ & $\mathrm{D}$ \\
\hline \multirow[t]{2}{*}{$\mathrm{mm}$} & \multicolumn{6}{|c|}{$\mathrm{Nm}$} \\
\hline & \multicolumn{3}{|c|}{ Thickness $10 \mathrm{~mm}$} & \multicolumn{3}{|c|}{ Thickness $12 \mathrm{~mm}$} \\
\hline 10 & 23.91 & 31.77 & 20.02 & 14.38 & 26.98 & 10.02 \\
\hline 15 & 33.94 & 44.49 & 30.03 & 26.53 & 38.57 & 20.31 \\
\hline 20 & 34.93 & 41.13 & 30.02 & 29.59 & 37.93 & 25.19 \\
\hline 25 & 41.68 & 54.24 & 35.09 & 37.08 & 49.18 & 30.23 \\
\hline 30 & 52.73 & 66.78 & 49.7 & 42.48 & 54.3 & 35.04 \\
\hline
\end{tabular}


Vol. 65 (5): 2020

\begin{tabular}{|c|c|c|c|c|c|c|}
\hline 35 & 63.84 & 75.49 & 62.53 & 58.01 & 75.24 & 45 \\
\hline 40 & 66.38 & 84.64 & 61.21 & 59.01 & 77.46 & 50.08 \\
\hline 45 & 68.94 & 82.7 & 60.5 & 74.14 & 92.73 & 60.15 \\
\hline 50 & 74.08 & 86.41 & 68.26 & 73.76 & 87.76 & 66 \\
\hline & \multicolumn{6}{|c|}{ Thickness $18 \mathrm{~mm}$} \\
\hline 10 & 29.78 & 37.8 & 25.02 & 31.01 & 41.07 & 25.01 \\
\hline 15 & 50.2 & 64.92 & 45 & 59.83 & 77.96 & 50 \\
\hline 20 & 69.17 & 86.62 & 60.04 & 66.04 & 83.62 & 55.1 \\
\hline 25 & 80.68 & 107.93 & 70 & 75.64 & 107.54 & 65 \\
\hline 30 & 100.52 & 140.95 & 90 & 83.71 & 121.305 & 65.44 \\
\hline 35 & 105.06 & 113.93 & 95.01 & 99.69 & 135 & 77.61 \\
\hline 40 & 123.5 & 160.02 & 110.01 & 110.02 & 132 & 91.23 \\
\hline 45 & 131.08 & 197.93 & 100 & 125.67 & 178.73 & 100.19 \\
\hline \multirow[t]{2}{*}{50} & 178.75 & 229.11 & 154.8 & 134.36 & 159.56 & 110.56 \\
\hline & \multicolumn{3}{|c|}{ Thickness $28 \mathrm{~mm}$} & \multicolumn{3}{|c|}{ Thickness $25 \mathrm{~mm}$} \\
\hline 10 & 27.77 & 93.65 & 20 & 27.47 & 51.28 & 19.87 \\
\hline 15 & 62.34 & 105.1 & 45.03 & 61.9 & 103.09 & 45.47 \\
\hline 20 & 69.23 & 164.97 & 55 & 68.71 & 120.97 & 55.01 \\
\hline 25 & 77.95 & 166.87 & 69.54 & 78.86 & 133.67 & 71.33 \\
\hline 30 & 88.84 & 134.95 & 75.01 & 92.49 & 156.87 & 83.21 \\
\hline 35 & 115.29 & 150.56 & 95.21 & 101.86 & 147.56 & 80.04 \\
\hline 40 & 112.31 & 196.66 & 100.02 & 106.29 & 193.66 & 90.03 \\
\hline 45 & 135 & 222.32 & 112.6 & 128.52 & 225.31 & 95.32 \\
\hline 50 & 152.32 & 243 & 121.52 & 149.55 & 240.4 & 110.81 \\
\hline
\end{tabular}

Tab. 3: Maximum torque values for OSB comminution, where: $A$-width, $B$ - arithmetic mean, $C$ - maximum value, $D$ - minimum value.

\begin{tabular}{|c|c|c|c|c|c|c|}
\hline $\mathrm{A}$ & $\mathrm{B}$ & $\mathrm{C}$ & $\mathrm{D}$ & $\mathrm{B}$ & $\mathrm{C}$ & $\mathrm{D}$ \\
\hline $\mathrm{mm}$ & \multicolumn{7}{|c|}{$\mathrm{Nm}$} \\
\hline & \multicolumn{7}{|c|}{ Thickness $12 \mathrm{~mm}$} & \multicolumn{3}{c|}{ Thickness $16 \mathrm{~mm}$} \\
\hline 10 & 19.62 & 26.32 & 17.01 & 21.38 & 25.43 & 16.78 \\
\hline 15 & 20.66 & 25.31 & 18.12 & 26.01 & 33.12 & 20.32 \\
\hline 20 & 31.93 & 40.06 & 26.19 & 37.98 & 53.49 & 32.02 \\
\hline 25 & 34.54 & 44.27 & 30.13 & 56.52 & 73.25 & 50.21 \\
\hline 30 & 40.92 & 48.72 & 35.29 & 64.01 & 91.07 & 55.37 \\
\hline 35 & 52.18 & 82.15 & 45.02 & 79.21 & 112.11 & 71.2 \\
\hline 40 & 61.96 & 79.59 & 53.23 & 90.17 & 103.7 & 80.33 \\
\hline 45 & 73.13 & 95.18 & 65.56 & 97.24 & 112.33 & 85.06 \\
\hline 50 & 76.52 & 104.24 & 70.12 & 105.83 & 132.32 & 91.71 \\
\hline & \multicolumn{7}{|c|}{ Thickness $18 \mathrm{~mm}$} & & Thickness $26 \mathrm{~mm}$ \\
\hline 10 & 37.32 & 50.22 & 27.52 & 43.83 & 65.77 & 35.02 \\
\hline 15 & 61.28 & 80.29 & 48.01 & 81.39 & 95.55 & 69.34 \\
\hline 20 & 81.48 & 126.99 & 69.21 & 92.86 & 84.47 & 111.42 \\
\hline 25 & 95.81 & 131.04 & 80.12 & 129.43 & 177.13 & 110.04 \\
\hline
\end{tabular}




\begin{tabular}{|l|l|l|l|l|l|l|}
\hline 30 & 119.39 & 156.07 & 95.06 & 140.21 & 215.86 & 120.05 \\
\hline 35 & 129.09 & 157.99 & 115.02 & 192.02 & 277.86 & 148.93 \\
\hline 40 & 151.43 & 198.06 & 129.87 & 227.79 & 301.31 & 198.56 \\
\hline 45 & 169.49 & 201.98 & 135.98 & 270.71 & 344.817 & 231.86 \\
\hline 50 & 198.21 & 227.48 & 153.67 & 276.95 & 418.51 & 250.01 \\
\hline
\end{tabular}

Tab. 4: Maximum torque values for MDF comminution, where: $A$ - width, $B$ - arithmetic mean, $C$ - maximum value, $D$ - minimum value.

\begin{tabular}{|c|c|c|c|c|c|c|}
\hline $\mathrm{A}$ & $\mathrm{B}$ & $\mathrm{C}$ & $\mathrm{D}$ & $\mathrm{B}$ & $\mathrm{C}$ & $\mathrm{D}$ \\
\hline $\mathrm{mm}$ & \multicolumn{6}{|c|}{$\mathrm{Nm}$} \\
\hline & \multicolumn{3}{|c|}{ Thickness $3 \mathrm{~mm}$} & \multicolumn{3}{|c|}{ Thickness $8 \mathrm{~mm}$} \\
\hline 10 & 11.34 & 15.78 & 10.21 & 23.48 & 28.23 & 19.02 \\
\hline 15 & 13.2 & 19.7 & 12.33 & 30.42 & 27.3 & 25.39 \\
\hline 20 & 16.28 & 21.06 & 14.12 & 39.46 & 53.26 & 30.92 \\
\hline 25 & 19.42 & 21.28 & 18.36 & 44.56 & 54.18 & 33.45 \\
\hline 30 & 25.09 & 27.99 & 21.02 & 48.33 & 56.98 & 36.21 \\
\hline 35 & 26.39 & 31.57 & 22.15 & 54.43 & 63.85 & 35.95 \\
\hline 40 & 28.43 & 32.14 & 25.44 & 60.62 & 78.65 & 45.35 \\
\hline 45 & 30.15 & 35.45 & 25.56 & 65.56 & 71.67 & 51.99 \\
\hline \multirow[t]{2}{*}{50} & 33.87 & 35.52 & 27.28 & 74.62 & 79.65 & 50.3 \\
\hline & \multicolumn{3}{|c|}{ Thickness $10 \mathrm{~mm}$} & \multicolumn{3}{|c|}{ Thickness $14 \mathrm{~mm}$} \\
\hline 10 & 20.28 & 24.29 & 18.03 & 14.55 & 20.68 & 12.45 \\
\hline 15 & 28.23 & 34.56 & 26.97 & 23.56 & 28.34 & 20.11 \\
\hline 20 & 35.58 & 43.24 & 32.09 & 33.65 & 40.56 & 31.92 \\
\hline 25 & 43.19 & 49.81 & 39.12 & 38.33 & 48.87 & 55.07 \\
\hline 30 & 45.53 & 51.72 & 42.01 & 41.53 & 57.12 & 38.54 \\
\hline 35 & 55.21 & 65.87 & 50.07 & 66.95 & 79.23 & 60.23 \\
\hline 40 & 57.16 & 62.05 & 55.46 & 71.95 & 87.69 & 63.09 \\
\hline 45 & 70.52 & 82.64 & 61.21 & 78.17 & 87.34 & 71.22 \\
\hline \multirow[t]{2}{*}{50} & 75.59 & 92.68 & 66.94 & 84.86 & 99.83 & 77.39 \\
\hline & \multicolumn{3}{|c|}{ Thickness $20 \mathrm{~mm}$} & & & \\
\hline 10 & 51.53 & 65.86 & 45.29 & & & \\
\hline 15 & 81.3 & 93.19 & 75.05 & & & \\
\hline 20 & 89.87 & 105.85 & 81.88 & & & \\
\hline 25 & 103.59 & 112.78 & 92.64 & & & \\
\hline 30 & 115.8 & 136.56 & 91.34 & & & \\
\hline 35 & 120.47 & 131 & 95.56 & & & \\
\hline 40 & 151 & 175.46 & 129.76 & & & \\
\hline 45 & 193.89 & 236.94 & 154.35 & & & \\
\hline 50 & 230.45 & 311.23 & 211.23 & & & \\
\hline
\end{tabular}

Actual torque dynamic characteristics of the working unit of the Macalister MQS2800 wood chipper exhibit certain variability, which is attributable to a sudden and step-like cyclic nature of the comminution process. The determined values are also influenced by interference caused, for example, by non-ideal balancing of the rotary parts of the working unit of the wood 
chipper. Nevertheless, the recorded data constitute a valuable source of information in view of designing and operating such a type of machinery. It is also possible to observe typical nature of the occurring changes and to determine their scale.

The unloaded working unit generates a torque of approx. $10 \mathrm{Nm}$ which results from the internal resistances of the mill, e.g. friction in the bearings. The comminution process generates a variable characteristic, which results from cutting orthotropic plant-based materials with anisotropic structures. Due to the comminution of the specimens said, it is possible to determine the variability characteristic of torque according to the geometry of the material subject to grinding (Fig. 4).

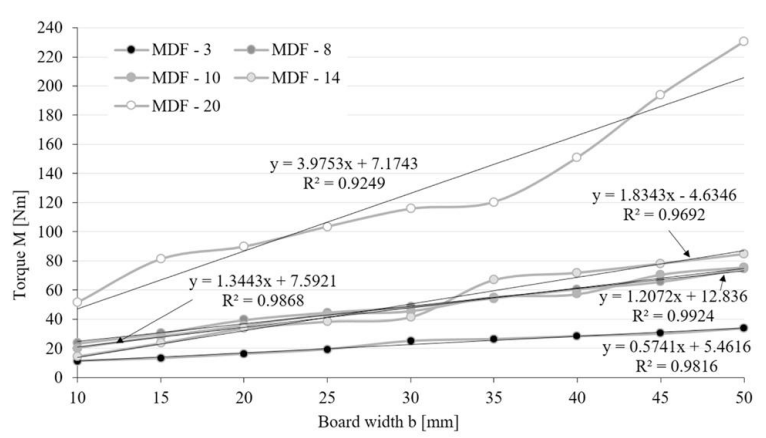

Fig. 4. Torque vs. width (of board under comminution) curves in the comminution process, taking into consideration the material and width, where at the legend of the graphs are indicated characteristics adequate for the line trend of the curves shown.

The collected data indicate that the torque value increases with increasing cross-section of the board under comminution, which is caused by a growing cutting area. The occurring changes may be acknowledged linear with sufficient approximation. It can be noticed that in the case of similar cross-sections, the highest resistance is generated by a MDF, followed by an OSB. The lowest value of the cutting force is required while comminuting a particle board. It is worth stressing that the use of surface laminate increases a board's shear resistance, most probably because of high hardness of that layer. The maximum torque value in the comminution process depends on the number of blades involved (Tab. 5).

Tab. 5: Percentage involvement of the second blade according to the thickness of the board subject to comminution; $G$-thickness; $H-\alpha$ angle value, $J$ - number of operating blades, $P$ - percentage involvement of the other blade in the cutting process.

\begin{tabular}{|c|c|c|c|c|c|c|c|c|c|c|}
\hline $\mathrm{G}(\mathrm{mm})$ & 3 & 8 & 10 & 12 & 14 & 18 & 20 & 25 & 26 & 28 \\
\hline$H\left({ }^{\circ}\right)$ & 21.28 & 35.1 & 39.4 & 43.34 & 47.01 & 53.78 & 56.94 & 64.42 & 65.85 & 68.68 \\
\hline$J(-)$ & 1 & 1 & 1 & 1 & 2 & 2 & 2 & 2 & 2 & 2 \\
\hline$P(\%)$ & 0 & 0 & 0 & 0 & 0.94 & 4.72 & 6.8 & 12.5 & 13.73 & 16.26 \\
\hline
\end{tabular}

Basing upon the tool geometry and the grinding process performed by means of a single cylinder wood chipper shown in Fig. 5 one may determine the number of the blades involved, according to the thickness of material subject to comminution. For a tool with eight symmetrically arranged blades, in the comminution process involved are two blades if the angle between the cutter's blade and the face of the piece under comminution $\alpha$ is $>45^{\circ}$. 


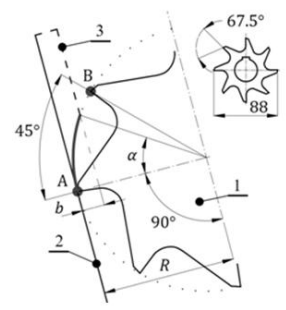

Fig. 5. Geometry of comminution process with a single cylinder wood chipper, where: 1 - grinding cutter, 2 - pressure plate, 3 - material under comminution, $L$ - length of surface under comminution, $b$-thickness of material under comminution, $R$-blade radius of the mill, $\alpha$-theoretical angle required for cutting the material through, $A$-vertex of the first blade, $B$-vertex of the second blade.

The percentage involvement of the other blade in the cutting process $P$ can be found from Eq. 1:

$$
\mathrm{P}=\frac{\left(\alpha-45^{\circ}\right) \cdot 100}{\alpha}(\%)
$$

where: $\alpha$ is the angle between the cutter's blade and the face of the piece being comminuted.

Comparing the results obtained from the comminution of pine wood beams, sized $18 \times 18 \mathrm{~mm}$ (Warguła et al. 2019) and of beams of particle board, having similar sizes, viz. $(18 \times 20 \mathrm{~mm})$, OSB $(18 \times 20 \mathrm{~mm})$ and MDF $(20 \times 20 \mathrm{~mm})$, it can be estimated that the torque value in the comminution of industrial furniture waste is lower and lies in an interval from $30 \%$ to $49 \%$. Basing upon the geometry of waste available in a factory or the geometry of the working unit and the feeding chute of the machine, it is possible to estimate the load on the driving unit. It is advantageous to select such a drive whose power does not significantly exceed the value resulting from the torque indispensable for comminuting the waste. This is of particular significance since the power for the driving unit is one of the fundamental factors influencing the energy consumption of the mill. Such a conclusion is corroborated by the test results (Facello et al. 2013, Manzone 2015, Shahid et al. 2019) concerning the comminution of tree trunks and branches with wood chippers which have the drive units with diversified power values (Fig. 6).

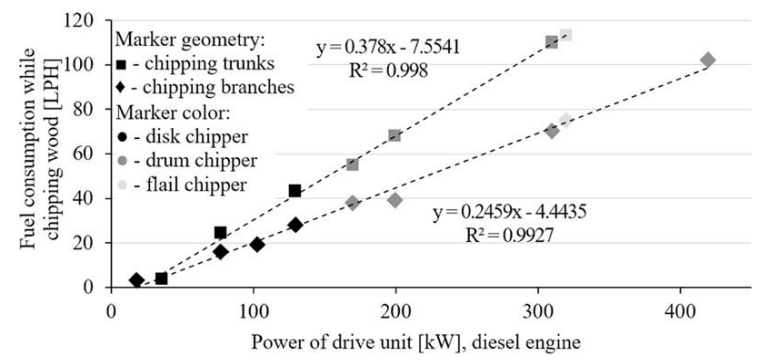

Fig. 6. Fuel consumption of heavy duty, self-ignition engined industrial wood chipper (elaborated basing upon results of investigations (Facello et al. 2013, Manzone 2015, Shabid et al. 2019).

It was proved that among many factors influencing the energy consumption in the comminution process, the power of the drive unit exerts the greatest influence upon energy 
consumption. A limitation of energy consumption during the operation of such a machinery is supported by adaptive systems (Warguła et al. 2017), alternative supply sources of drives (Szpica and Czaban 2014) as well as by innovative working units (Macok et al. 2018). However, it is adequate selection of the drive power vs. real power demand to guarantee the most efficient utilization of the energy supplied for the comminution process.

Tab. 6: Linear function approximation coefficients for a torque change dependent upon the thickness of materials under comminution and their types.

\begin{tabular}{|l|c|c|}
\hline \multicolumn{1}{|c|}{ Material - thickness $(\mathrm{mm})$} & Linear approximation & Coeff. of determination $\left(\mathrm{R}^{2}\right)$ \\
\hline PB laminated -10 & $\mathrm{y}=1.3025 \mathrm{x}+12.085$ & 0.968 \\
\hline PB laminated -18 & $\mathrm{y}=3.2385 \mathrm{x}-0.6293$ & 0.9609 \\
\hline PB laminated -28 & $\mathrm{y}=2.7989 \mathrm{x}+9.482$ & 0.9668 \\
\hline PB not laminated -12 & $\mathrm{y}=1.5337 \mathrm{x}+0.0969$ & 0.9758 \\
\hline PB not laminated -18 & $\mathrm{y}=2.4098 \mathrm{x}+15.037$ & 0.9808 \\
\hline PB not laminated -25 & $\mathrm{y}=2.6211 \mathrm{x}+11.994$ & 0.9617 \\
\hline OSB -12 & $\mathrm{y}=1.5424 \mathrm{x}-0.5532$ & 0.9769 \\
\hline OSB -16 & $\mathrm{y}=2.2619 \mathrm{x}-3.5949$ & 0.9886 \\
\hline OSB -18 & $\mathrm{y}=3.8046 \mathrm{x}+1.8074$ & 0.9941 \\
\hline OSB -26 & $\mathrm{y}=6.1096 \mathrm{x}-21.601$ & 0.9816 \\
\hline
\end{tabular}

During the tests, absolute increment values were also applied for analyzing the effect of the respective variables exerted upon the experimental results. So as to estimate the scale of the occurring changes there were used torque increments vs. specimen thickness $\Delta \mathrm{M}_{1}$, torque increments vs. specimen widths $\Delta \mathrm{M}_{2}$ and torque increments $\Delta \mathrm{M}_{3}$, in line with the relationships (2) - (4):

$$
\begin{array}{ll}
\Delta M_{1}=M_{\text {gmax }}-M_{\text {gmin }} & \text { (N.m) } \\
M_{2}=M_{\text {bmax }}-M_{\text {bmin }} & \text { (N.m) } \\
\Delta M_{3}=M_{r \text { max }}^{\text {MDF }}-M_{\text {rmin }} & \text { (N.m) }
\end{array}
$$

where: $M_{g \max }$ and $M_{\text {gmin }}$ stand, respectively, for the highest and the lowest average torque values for the same width and type, but with different thicknesses, $M_{b \max }$ i $M_{b \min }$ are, respectively, the highest and the lowest torque value for a MDF specimen of the same thickness and type but with different widths, $\mathrm{M}_{\mathrm{rmax}}^{M D F}$ means the average torque value for a $\mathrm{MDF}$ specimen with a given thickness and width, and eventually, $M_{\text {rmin }}$ stands for average torque values for a specimen with the same width and similar thickness, but of other type of material.

Material from a laminated and non-laminated plywood and OSB, $18 \mathrm{~mm}$ thick, was chosen for calculating the last coefficient. In the case of the MDF board, the closest thickness value was chosen, viz. $20 \mathrm{~mm}$. For the nature of the specimens under examination (wastes), it was impossible to select a $18 \mathrm{~mm}$ thick MDF. The respective graphs are shown in Figs. 7-9.

An analysis of the presented graphs allows one to conclude that the highest absolute increment of the average torque value, according to the thickness, amounted to $233.12 \mathrm{Nm}$ (Fig. 7) and was recorded for an OSB. Basing thereupon it can be stated that in line with the tests performed, the thickness of the pieces subject to comminution has the crucial effect upon the torque required in this process. The reason for such a great increment is that as then specimen thickness grows; the share of the respective cutting blades in the comminution process will also increase. The more 
blades contact the material, the higher demand for driving torque. The highest absolute increment of the average torque value according to the specimen width was $200.43 \mathrm{Nm}$. An analysis of the graph in Fig. 8 permits to ascertain that a constant increase in the torque value depends upon the width, which results from an increased cross section of the material under comminution - the larger the board area, the greater torque demand. The values shown in Fig. 9 are shown with previous reservation pertinent to the specimen thickness. Nevertheless, it can be noticed that the largest change recorded is $96.09 \mathrm{Nm}$. Of course, the type of material exerts a significant effect upon the maximum recorded values of torque required for grinding the material. However, during the tests performed similar materials were subject to comminution. Most probably that is why for similar specimen thicknesses obtained were average maximum torque values which differ one from another to the least possible extent in relation to the thickness and width.

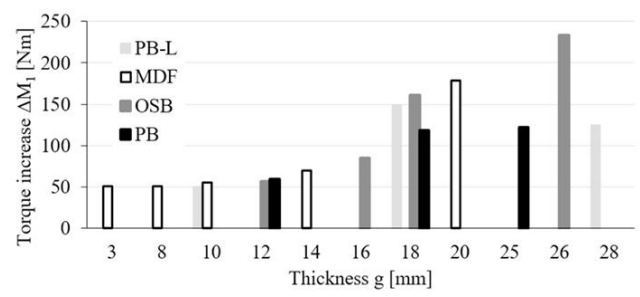

Fig. 7. Torque increment $\Delta M_{1}$ according to the thickness of specimens.

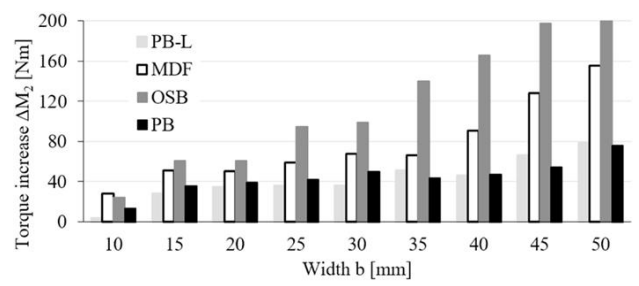

Fig. 8. Torque increment $\Delta M_{2}$ according to the width of specimens.

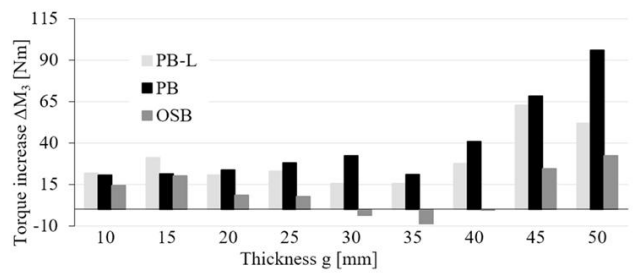

Fig. 9. Torque increment $\Delta M_{3}$ according to the type of specimens.

\section{CONCLUSIONS}

The crucial conclusions concerning the effect of the type and size of industrial furniture board waste exerted upon the torque during the comminution by means of a wood chipper are as follows: (1) In the process of comminution of industrial furniture board waste, the torque value increases approximately linearly with growing cross sectional thickness. The highest recorded 
absolute change of the average value of the driving torque is around $233 \mathrm{Nm}$. (2) In the process of comminution of industrial furniture board waste, the torque value increases with growing cross sectional width. The highest recorded absolute change of the average value of the driving torque is around $200 \mathrm{Nm}$. (3) In the process of comminution of industrial furniture board waste, the torque value changes with the change of the material type. The highest recorded absolute change of the average value of the torque referred to MDF boards is around $96 \mathrm{Nm}$. (4) The maximum torque for materials with similar thickness is required for comminuting a MDF, followed by an OSB, and the smallest force is required for comminuting a particle board. (5) Laminated particle boards entail a higher torque for the comminution than non-laminated ones do. (6) It can be estimated that for the comminution of furniture wastes - if compared to wood (pine) wastes - the required power of the driving unit is lower by about 30\%. (7) An increased number of cutting blades (for a constant thickness of a part subject to comminution) increases the value of the torque required. (8) The choice of the tool geometry according to the thickness of waste being comminuted - in which case only one cutting blade is necessary - may limit the power demand of the drive unit, and thus, decrease the energy consumption in the process. (9) The significance of the tests shown in this paper is derived from the set of the results obtained. Those results can be utilized for works related to the development and validation of mathematical models to describe the power demand in the comminution process. They also constitute a set of input parameters which may be used in designing comminuting machinery operated with a single cylinder cutter.

\section{REFERENCES}

1. Akyildiz, M.H., Dogan, K., Kaymakci, A., 2018: The impact of density and mixture ratio of melamine on some properties of oriented strand board. Maderas. Ciencia y tecnología 20(3): 417-430.

2. Akyüz, K.C., Nemli, G., Baharoğlu, M., Zekoviç, E., 2010: Effects of acidity of the particles and amount of hardener on the physical and mechanical properties of particleboard composite bonded with urea formaldehyde. International Journal of Adhesion and Adhesives 30(3): 166-169.

3. Ayrilmis, N., Candan, Z., White, R., 2007: Physical, mechanical, and fire properties of oriented strandboard with fire retardant treated veneers. Holz als Roh-und Werkstoff 65(6): 449-458.

4. Chuchała, D., Orłowski, K., 2018: Forecasting values of cutting power for the sawing process of impregnated pine wood on band sawing machine. Mechanik 2018(8-9): 766-768.

5. de Barros Filho, R.M., Mendes, L.M., Novack, K.M., Aprelini, L.O., Botaro, V.R., 2011: Hybrid chipboard panels based on sugarcane bagasse, urea formaldehyde and melamine formaldehyde resin. Industrial Crops and Products 33(2): 369-373.

6. Durković, M., Mladenović, G., Tanović, L., Danon, G., 2018: Impact of feed rate, milling depth and tool rake angle in peripheral milling of oak wood on the cutting force. Maderas. Ciencia y tecnología 20(1): 25-34.

7. Džinčić, I., Skakić, D., 2012: Determining the parameters of wood machinability as a function of tangential cutting force during the process of machining wood by routing. Wood Research 57(1): 161-172.

8. Facello, A., Cavallo, E., Magagnotti, N., Paletto, G., Spinelli, R., 2013: The effect of chipper cut length on wood fuel processing performance. Fuel processing technology 116: 228-233. 
9. Ganev, S., Gendron, G., Cloutier, A., Beauregard, R. 2007: Mechanical properties of MDF as a function of density and moisture content. Wood and fiber science 37(2): 314-326.

10. Guo, X., Li, R., Cao, P., Ekevad, M., Cristovao, L., Marklund, B., Grönlund, A., 2015: Effect of average chip thickness and cutting speed on cutting forces and surface roughness during peripheral up milling of wood flour/polyvinyl chloride composite. Wood Research 60: $147-156$.

11. Kopecký, Z., Hlásková, L., Orlowski, K.A., 2014: An innovative approach to prediction energetic effects of wood cutting process with circular-saw blades. Wood Research 59(5): 827-834.

12. Kopecký, Z., Hlásková L., Solař, A., Nesázal P., 2019: Cutting forces quasi-orthogonal CNC milling. Wood Research 64(5): 879-890.

13. Krauss, A., Piernik, M., Pinkowski, G., 2016: Cutting power during milling of thermally modified pine wood. Drvna Industrija 67(3): 215-222.

14. Król, D., 2008: Thermal destruction of hazardous waste - copper and lead emissions. Archives of Waste Management and Environmental Protection 7: 43-50.

15. Kuvik, T., Krilek, J., Kovác, J., Štefánek, M., Dvorak, J., 2017: Impact of the selected factors on the cutting force when using a chainsaw. Wood Research 62: 807-814.

16. Macko, M., Tyszczuk, K., Śmigielski, G., Mroziński, A., 2018: Utility of an unitary shredding method to evaluate the conditions and selection of constructional features during grinding. In: MATEC Web of Conferences, Proceedings of the Machine Modelling and Simulations, Sklené Teplice, Slovak Republic, 5-8 September 2017; EDP Sciences: Lez Ili, France, 2018; Vol. 157, 05016: 1-7.

17. Mandić, M.D., Porankiewicz, B., Danon, G.J., 2015: An attempt at modelling of cutting forces in oak peripheral milling. BioResources 10(3): 5489-5502.

18. Manzone, M., 2015: Energy consumption and CO2 analysis of different types of chippers used in wood biomass plantations. Applied energy 156(C): 686-692.

19. Narlığlu, N., Salan, T., Çetin, N.S., Alma, M.H., 2018: Evaluation of furniture industry wastes in polymer composite production. Mobilya ve Ahşap Malzeme Araştırmaları Dergisi 1(2): 78-85.

20. Orłowski, K., Ochrymiuk, T., 2017: A newly-developed model for predicting cutting power during wood sawing with circular saw blades. Maderas. Ciencia y tecnología 19(2): 149-162.

21. Orlowski, K.A., Ochrymiuk, T., Atkins, A., Chuchala, D., 2013: Application of fracture mechanics for energetic effects predictions while wood sawing. Wood Science and Technology 47(5): 949-963.

22. Pavlov, A.K., 2019: Factors of supply chain development in the market of furniture products in Russia. In Логистика: современные тенденции развития, Pp 299-303.

23. Porankiewicz, B., Axelsson, B., Grönlund, A.A., Marklund, B., 2011: Main and normal cutting forces by machining wood of Pinus sylvestris. BioResources 6(4): 3687-3713.

24. Porankiewicz, B., Goli, G., 2014: Cutting forces by Oak and Douglas fir machining. Maderas. Ciencia y tecnología 16(2): 199-216.

25. Pritchard, J., Ansell, M.P., Thompson, R.J.H., Bonfield, P.W., 2001: Effect of two relative humidity environments on the performance properties of MDF, OSB and chipboard. Wood Science and Technology 35(5): 405-423.

26. Reczulski, M., 2015: Analysis of the construction and operation of system wood chipping and transfer chips. Wood Research 60(4): 671-678.

27. Rydzkowski, T., Michalska-Pożoga, I., 2016: Analysis of intensity of changes in the moisture content of wood chips in the production of wood polymer composites during drying and storage processes. Wood Research 61(3): 457-464. 
28. Shahid, L.A., Amjad, N., Siddhu, M.A.H., 2019: Adaptation and performance evaluation stof a tractor operated wood chipper shredder. Pakistan Journal of Agricultural Research 32(1): 197-204.

29. Szpica, D., Czaban, J., 2014: Operational assessment of selected gasoline and LPG vapour injector dosage regularity (Benzino ir suskystintu duju garu dozavimo reguliarumo purkstuku operacinis vertinimas). Mechanika 20(5): 480-489.

30. Warguła, Ł., Adamiec, J. M., Waluś, K. J., Krawiec, P., 2018: The characteristics analysis of torque and rotation speed of working unit of branch grinder-introductory research. In: MATEC Web of Conferences, Proceedings of the Machine Modelling and Simulations, Sklené Teplice, Slovak Republic, 5-8 September 2017; EDP Sciences: Lez Ili, France, 2018; Vol. 157, 01021: 1-8.

31. Warguła Ł., Wojtkowiak D., Waluś K. J., Krawiec P., Wieczorek B., 2017: The analysis of the efficiency of the control system of wood chipper's driver with spark-ignition engine based on Skoda combustion engine 1.4 59kW., Transport Means 2017. In: Proceedings of the $21^{\text {st }}$ International Scientific Conference, September 20-22, 2017, Juodkrante, Lithuania. Part 2: Pp 452-458.

32. Wasielewski, R., 2019: The use of engineered wood wastes for energy production. Archives of Waste Management and Environmental Protection 21(1): 1-8.

33. Wasielewski, R., Bałazińska, M., 2017: Energy recovery from waste in the aspect of electricity and heat qualification as coming from renewable Energy sources and participation the system of emissions trading. Ecological Engineering 18(5): 170-178.

34. Yu, S.T., Yang, C.M., Ren, C.Q. Luo, G., 2012: Cutting force analysis of large branch crusher based on the finite element. In Applied Mechanics and Materials 152: 900-905.

Eukasz WarguŁa*, Mateusz Kukla

Poznan University of Technology

Faculty of Mechanical Engineering

Institute of Machine Design

Poznań

Poland

*Corresponding author: lukasz.wargula@put.poznan.pl 
